\title{
Correction to: Developing achievable alternate futures for key challenges during the UN Decade of Ocean Science for Sustainable Development
}

\author{
Kirsty L. Nash (D) Karen Alexander - Jess Melbourne-Thomas • \\ Camilla Novaglio - Carla Sbrocchi - Cecilia Villanueva - Gretta T. Pecl
}

Published online: 31 January 2021

(C) Springer Nature Switzerland AG 2021

\section{Correction to: Rev Fish Biol Fisheries https://doi.org/10.1007/s11160-020- 09629-5}

The author name was incorrectly published in the original publication of the article. The correct version of author name is provided in this correction. The correct name of the author is Camilla Novaglio.

The original article has been corrected.

Publisher's Note Springer Nature remains neutral with regard to jurisdictional claims in published maps and institutional affiliations.

The original article can be found online at https:// doi.org/10.1007/s11160-020-09629-5.

K. L. Nash $(\bowtie) \cdot$ K. Alexander · J. Melbourne-Thomas C. Novaglio - C. Sbrocchi - C. Villanueva - G. T. Pecl Centre for Marine Socioecology, University of Tasmania, Private Bag 129, Hobart, TAS 7001, Australia e-mail: nashkirsty@gmail.com

K. L. Nash · K. Alexander - C. Novaglio - G. T. Pecl Institute for Marine and Antarctic Studies, University of Tasmania, Private Bag 129, Hobart, TAS 7001, Australia

J. Melbourne-Thomas · C. Novaglio

CSIRO Oceans and Atmosphere, Castray Esplanade,

Battery Point, TAS 7004, Australia

C. Sbrocchi

Faculty of Arts and Social Sciences, University of Technology Sydney, PO Box 123, Broadway 2007, Australia 